\title{
FOUR-QUADRANT SPEED ESTIMATION BASED ON MODEL REFERENCE ADAPTIVE SYSTEM
}

\author{
Z. M. Salem, M. M. Khater, S. A. Kalilah, and S. A. Mahmoud \\ Electrical Engineering Department, Faculty of Engineering, \\ Minoufiya University, Shebin El-Kom, Egypt
}

\begin{abstract}
Speed estimation methods for sensorless induction motor drives can be divided into two types. The first is based on acquiring data about fundamental components of stator currents and voltages. The second is based on the injection of high-frequency signals carried on stator voltages or currents. The latter type allows stable operation around zero frequency, and low speeds, However, besides its complexity, it increases the losses and torque ripple. The former type is difficult to operate at low speeds. In this paper, a modified speed estimation method of the first type is proposed to improve the performance of a sensorless vector controller. The proposed method is based on model reference adaptive control (MRAC) that uses the stator current and rotor flux as state variables for estimating the speed. In this method, the stator current error is represented as a function of first degree of the estimated speed error. Therefore, the proposed method beside offering a four quadrant operation, produces fast speed estimation and is robust to parameter variations. The superiority of the proposed method is verified by simulation.

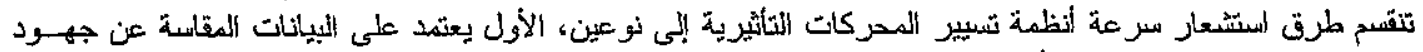

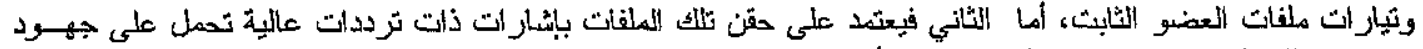

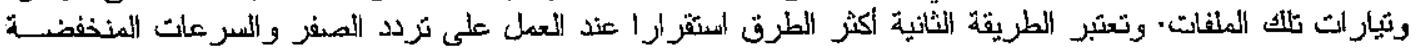

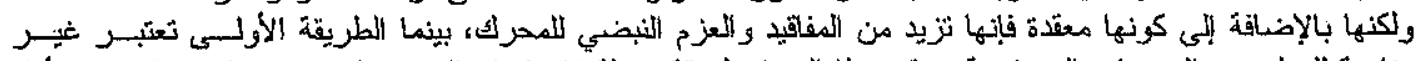

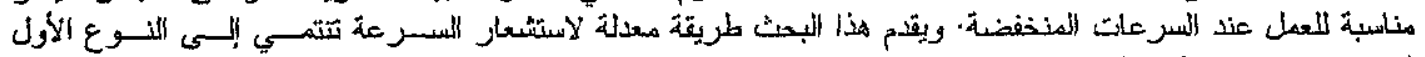

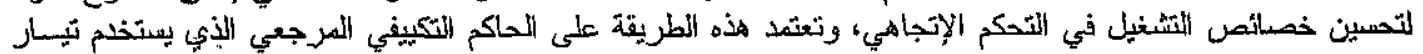

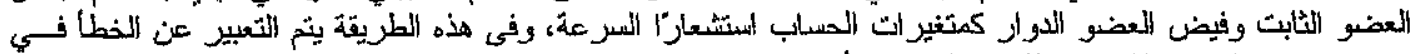

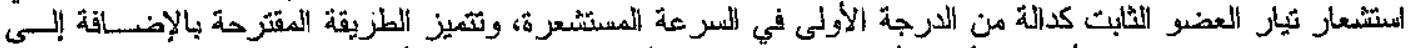

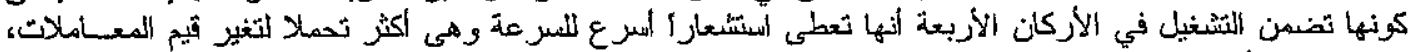

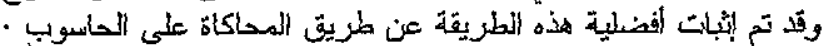

Keywords: Induction motor, sensorless control, vector control, variables, observers, modeling, identification, adaptive tuning.
\end{abstract}

\section{INTRODUCTION}

Induction motor drives have been thoroughly studied in the past few decades and many vector control strategies have been proposed, ranging from low cost to high performance applications. The indirect vector control of an induction motor requires precise speed information. Therefore, a speed sensor, such as a resolver or an encoder, is usually fixed to the rotor shaft to measure the motor speed. However, a speed sensor increases the cost and requires a data line to be connected between the control system and the motor. Thereby, any signal interference with such data line can adversely influence the operation of the control system. Furthermore, an exact servo control performance is sometimes required in an operating environment where the attachment of a speed sensor is impossible. In order to increase the reliability and reduce the cost of the drive, great effort has been made to eliminate the shaft speed or position sensor in most high performance induction motor drive applications [1-4].

Sensorless vector control that can precisely control an induction motor without a speed sensor has become an important research topic, resulting in the development of various speed estimation algorithms and sensorless control methods. The most commonly used algorithm for speed estimation is the model reference adaptive system (MRAS) [5]. In this algorithm, the rotor flux is estimated from the stator equation (considered to be the reference model, once it does not depend on the speed) and also using the rotor equation (adaptive model). The 
speed is then obtained by the use of an adaptive law having the cross product of the two estimated signals as inputs. Different ways may be used in this respect. The rotor flux can be used [1], or the back emf [2] to make a reference function, then the motor speed is estimated using model reference adaptive control (MRAC). The performance of these methods deteriorate at low speeds due to the increment of nonlinear characteristic. Speed estimation methods using MRAC are the most commonly used as they are easy to design and analyze [6-9]. The most effective would seem to be the rotor flux and back emf-based MRAC methods, however, they are inaccurate at low and zero speeds.

An adaptive flux observer can be constructed from the machine model equation. The model outputs are the estimated values of the stator current vector $\hat{i}_{S}$ and the rotor flux linkage vector $\hat{\lambda}_{r}$, respectively. Adding an error compensator to the model establishes the observer. The error vector computed from the model current and the machine current is used to generate correcting inputs to the electromagnetic subsystems that represent the stator and the rotor in the machine model.

In terms of classification, the adaptive flux observer schemes could also be treated as MRAS, where the motor is considered as the reference model and the observer is considered as the adaptive model.

The accuracy of the open loop estimation models deteriorates at low mechanical speed. The limit of acceptable performance depends on how precisely the model parameters matche the corresponding parameters of the actual machine. It is particularly at lower speed that parameter errors have significant influence on the steady state and dynamic performance of the drive system. The robustness against parameter mismatches and signal noise can be improved by employing closed loop observers to estimate the state variables, and the system parameters.

In this paper, a modified speed estimation method using MRAS to improve the performance of a sensorless vector controller is proposed. In this method, the stator current is used as the state variable to estimate the speed. Since the stator current error is represented as a function of estimated speed, the proposed method can provide four quadrant operation and is also more robust to parameter variations compared with other MRAS methods. The proposed method is verified by simulation.

\section{MATHEMATICAL MODEL OF AN INDUCTION MOTOR IN SYNCHRONOUS REFERENCE FRAME}

Choosing stator current and rotor flux as the state vector, the mathematical model of three-phase squirrelcage induction motor in the synchronous reference frame can be described as:

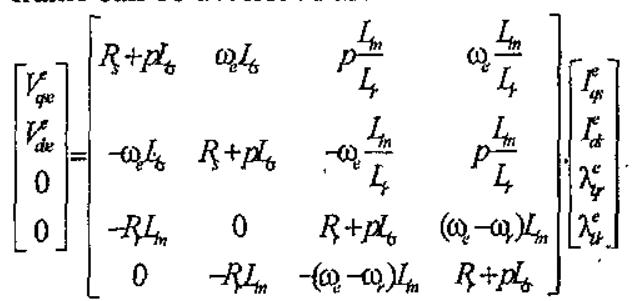

The electromechanical equation is also given by

$T_{\mathrm{e}}-T_{L}=J \frac{d \omega}{d t}+B \omega$

where the electromagnetic torque is expressed as;

$T_{e}=\frac{2}{3} \cdot \frac{L_{m}}{L_{r}}\left(I_{q s}^{c} \lambda_{d r}^{e}-I_{d s}^{e} \lambda_{q r}^{e}\right)$

Assuming the stator applied voltage $\mathrm{V}$ is known, and the stator current can be obtained directly via measurements, the flux vector can be obtained by integration as follows

$\lambda_{s}=\int\left(V-R_{s} I_{s}\right) d t$

This equation is often called the stator flux observer.

\section{INVESTIGATION OF ' DIFFERENT SENSORLESS STRATEGIES}

In this section, two different speed sensorless strategies for three-phase induction motor are investigated to illustrate the main difficulties associated with them. These strategies are the model reference adaptive system (MRAS) and speed observers based on either stator or rotor flux.

\subsection{Speed Estimation Based on MRAS Schemes}

Model reference adaptive system technique is usually applied in order to estimate the rotor speed. It is based on comparing the outputs of two estimator, one is called the reference model and the other is an adjustable model as shown in Fig. 1. The outputs of the two estimators may be the rotor flux, back emf or reactive power. The reference mode] does not involve the quantity to be estimated (the rotor speed $\omega_{r}$ ) and is considered as the voltage model. The adjustable model is the current model which is derived from the rotor equation. The error between the two quantities estimated by these models is used to drive a suitable adaptation mechanism to generate the estimated rotor speed; $\omega_{r}$ which in turn is used, for the developed 
current model. The block diagram for this method is shown in Fig. 1.

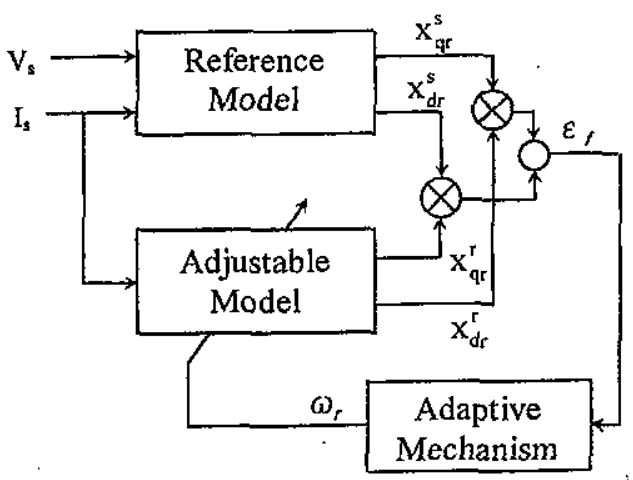

Fig. 1 Block diagram for Model Reference Adaptive System

The model reference approach makes use of the redundancy of two machine models of different structures that estimate the same state variable on the basis of different sets of input variables. Both models are referred to in the stationary reference frame. The first model which is the stator model (i.e. voltage model) serves as a reference model. Its output is the estimated vector (rotor flux, counter back EMF or reactive power) the superscript $s$ indicates that it originates from the stator model. The second model is the rotor model (i.e. current model) which serves as adaptive model. Its output is the estimated vector (rotor flux, counter back EMF or reactive power) the superscript $r$ indicates that it originates from the rotor model. This model estimates the rotor flux, counter back. EMF or reactive power from the measured stator current and a tuning signal. This signal is obtained through a proportional-integral (PI) controller from a scalar error signal, which is proportional to the angular displacement between the two estimated vectors obtained from the two models. As the error signal $\varepsilon$ gets minimized by the PI controller, the tuning signal approaches the actual speed of the motor. The rotor model as an adjustable one aligns its output vector with the output vector $s$ of the reference model.[1]

The output signals of the two models (quantities $x$ shown in Fig. 1) may be the back emf as shown in Fig. 2 , the reactive power as shown in Fig. 3 , or the rotor flux as shown in Fig. 4. It should be noted that back emf-based model reference adaptive system lacks robustness at low to zero speeds. Such method, as well as adaptive MRAS forms are all limited by the fact that the back emf vanishes at zero speed. The integration difficulty at this range of low frequency, low speed operation is the main problem of these methods.

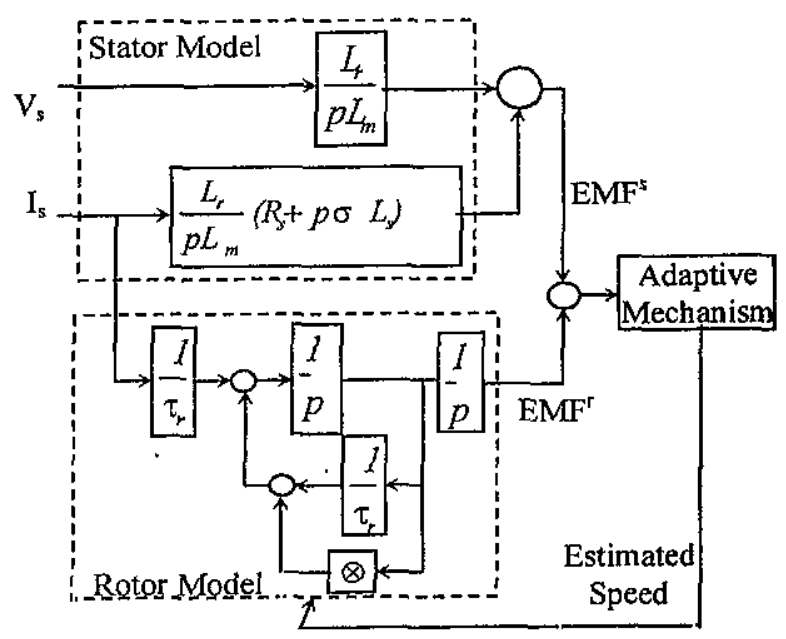

Fig. 2 MRAS based on counter EMF estimation

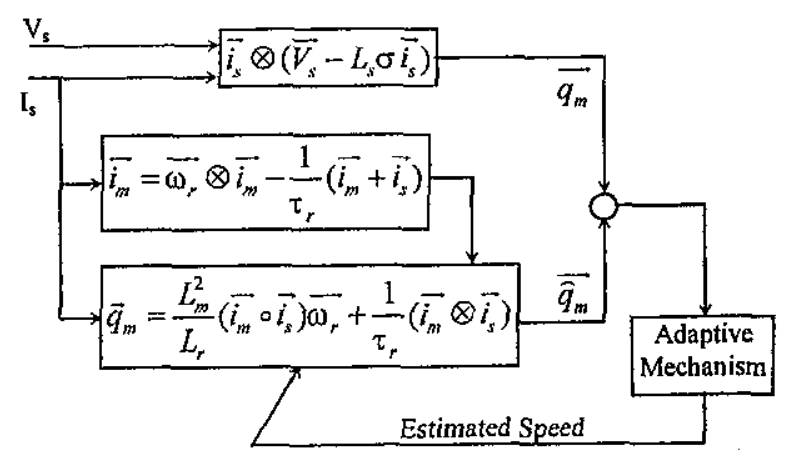

Fig. 3 MRAS based on counter reactive power estimation

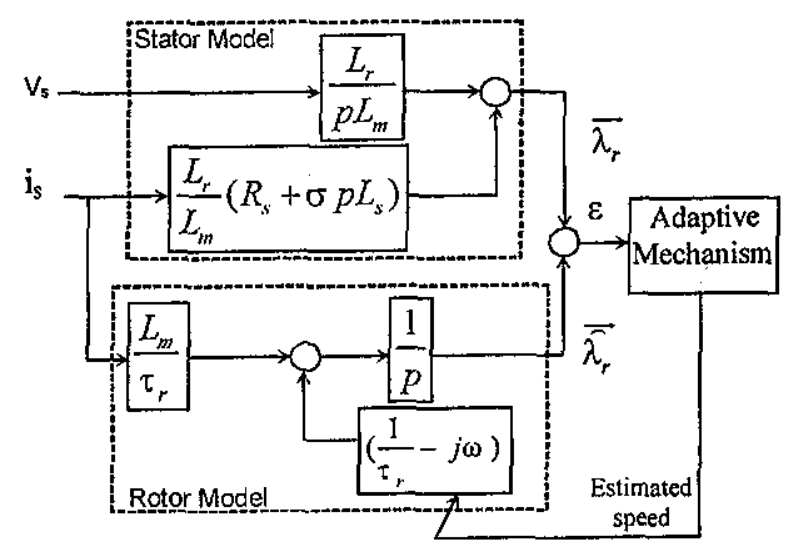

Fig. 4 MRAS based on rotor flux Estimation

The analysis of the rotor flux based MRAS is given here. The current model and the adaptive mechanism are described by the following expressions; 
$\lambda_{q r}^{s}=\frac{L_{r}}{L_{m}}\left(V_{s q}-i_{s q} R_{s}-L_{s} \sigma i_{s q}\right)$

$\lambda_{d r}^{s}=\frac{L_{r}}{L_{m}}\left(V_{s d}-i_{s d} R_{s}+L_{s} \sigma i_{s d}\right)$

Rotor flux obtained from rotor model

$$
\begin{aligned}
& \lambda_{d r}^{r}=\int \frac{L_{m} R_{r}}{L_{r}}\left(i_{s d}-\frac{R_{r}}{L_{r}} \lambda_{d r}-\omega_{r} \lambda_{q r}\right) \\
& \lambda_{q r}^{r}=\int \frac{L_{m} R_{r}}{L_{r}}\left(i_{s q}-\frac{R_{r}}{L_{r}} \lambda_{q r}+\omega_{r} \lambda_{d r}\right)
\end{aligned}
$$

Hence, the estimated speed is calculated as follows.

$$
\begin{aligned}
\hat{\omega} r= & k_{p}\left(\lambda_{q r}^{s} \lambda_{d r}^{s}-\lambda_{q r}^{r} \lambda_{d r}^{r}\right) \\
& +k_{i} \int_{0}^{T}\left(\lambda_{q r}^{s} \lambda_{d r}^{s}-\lambda_{q r}^{r} \lambda_{d r}^{r}\right) d t
\end{aligned}
$$

where $K_{P}$ and $K_{I}$ are the gains of adaptation mechanism.

A simulation program for a vector-controlled induction motor based on the present analysis is implemented using Matlab/Simulink. A block diagram of this simulation is shown in Fig. 5 , in which the motor speed is estimated by the present technique. The inputs for the drive controller are the reference speed $\omega_{\mathrm{r}}^{*}$, the reference flux $\lambda_{\text {ir }}$ and the load torque $T_{L}$. The outputs are the instantaneous currents, voltages, flux, speed and torque.

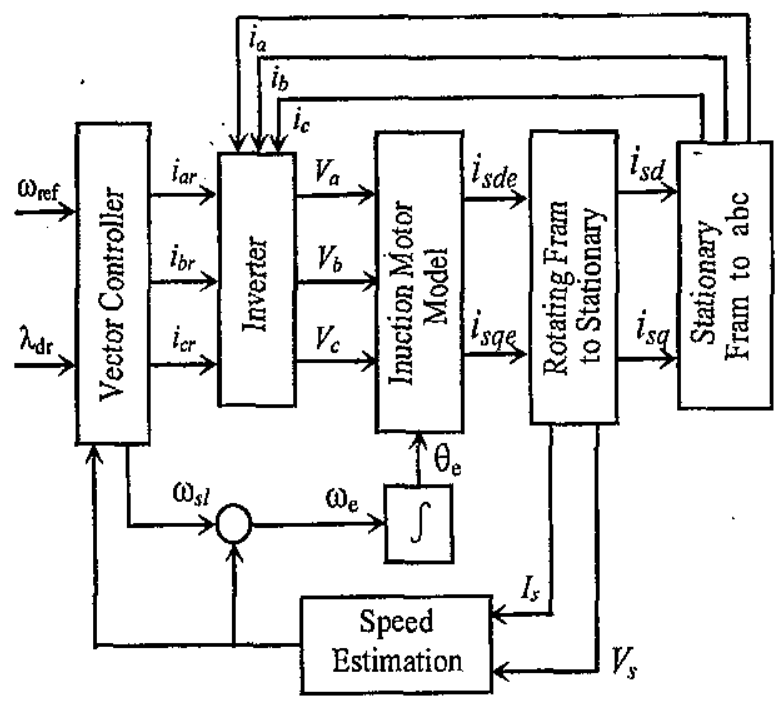

Fig 5. Block diagram for a vector-controlled induction motor based on speed estimation.
Figure 6 shows the speed measured from simulation model while Fig 7 shows the motor speed estimated by MRAS. The values of the controller parameters are large, so, the estimated speed is very noisy. Also the motor reaches the steady state with soft starting. The difference between the two curves is clear. Figure 8 shows three-phase currents with good wave form.

Figure 9 shows the developed motor torque. Figure 10 shows the rotor flux signals obtained from the voltage model and current model. It is clear that there is small phase error between the two signals. The adaptive controller attempts to drive this error to zero by aligning the two estimated signals from the current and voltage models. The accuracy of the speed estimation is entirely dependent upon the accuracy of the flux estimated from both the voltage and current models [12].

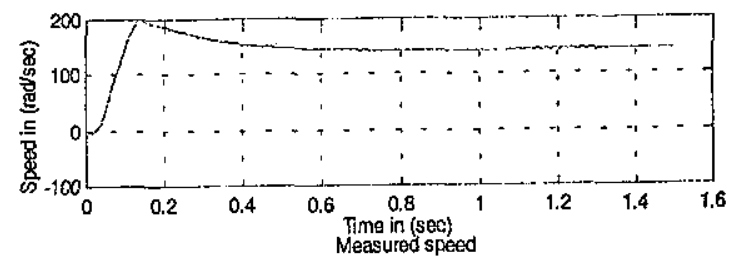

Fig. 6 The speed measured from simulation model.

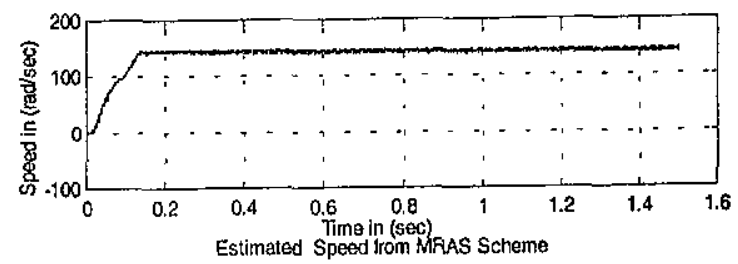

Fig. 7 The motor speed obtained from MRAS

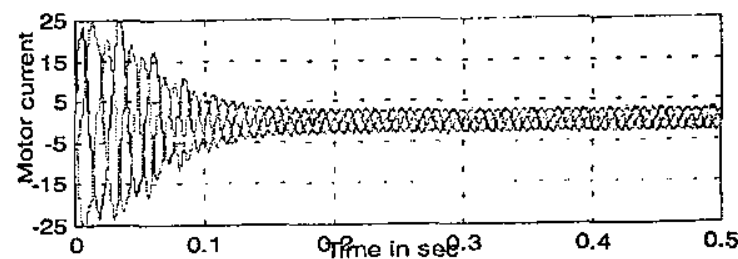

Fig. 8 The three-phase motor currents

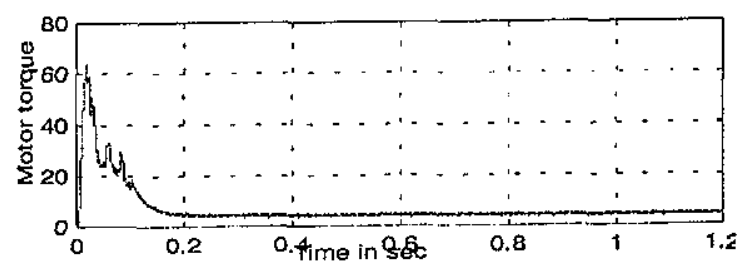

Fig. 9 The developed motor torque. 


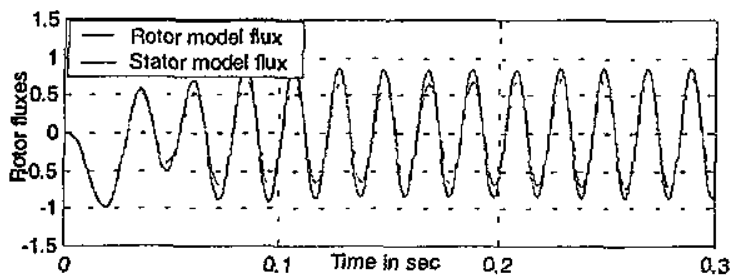

Fig. 10 The rotor fiux signals obtained from the voltage model and current model.

At high frequencies, the back emf dominates the resistance voltage drop and the flux estimate is relatively insensitive to the stator resistance. However, low speed estimation becomes difficult due to increased sensitivity to the stator resistance which is further accentuated by low frequency integration problems. To remove dc offset and avoid integration drift, a low pass filter integrator incorporating a state feedback is required. The original voltage model uses a pure integrator which causes drift.To avoid this problem the pure integrator is replaced by a low pass filter as shown Fig. 11. Since output of the modified voltage model would be different, the current model must be modified simultaneously. The modified voltage model consists of a voltage model and a high pass filter[13].

The MRAS speed estimator never works by $K_{p}$ and $\mathrm{K}_{\mathrm{I}}$ parameters. A method was suggested to determine the values of parameters $K_{p}$ and $K_{I}$ [13]. Also, the motor parameter variation and their effect on torque control was studied.

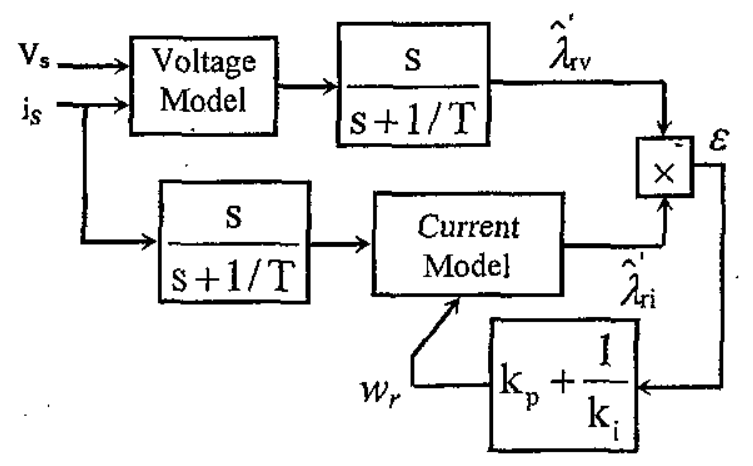

Fig. 11 Modified speed estimator.

\subsection{Speed Estimation Based on Adaptive Flux Observer}

An induction motor can be described, in a reference frame rotating with the motor angular velocity, by the following state equations:

$\frac{d}{d t} \bar{x}^{e}=\hat{A}_{1} \hat{x}^{e}+B_{1} v_{s}^{e}$
A state observer that provides estimates of both stator and Rotor flux is given by the following equation:

$\frac{d}{d t} \bar{x}^{e}=\hat{A}_{1} \hat{x}^{e}+B_{1} v_{s}^{e}+G\left[\hat{i}_{s}^{c}-i_{s}^{e}\right]$

When the motor speed is not measured, it is treated as an unknown parameter in the observer. By adding an adaptive scheme for estimating the rotor speed to the observer, both states and unknown parameters can be estimated simultaneously. The adaptive scheme is derived using Lyapunov theory [11].

Until now; few methods have been proposed for the state observer for induction motor. The only assumption made on the observer gain matrix $G$ is that the poles of the observer are stable. Usually, the poles of the observer are placed such that the observer error decreases faster than the induction motor transients [13].

The quantity $\mathrm{x}$ in Eqn. 11 may be stator flux or rotor flux. So, the speed observer is divided into two types according to which flux is used (rotor flux or stator flux) as follows.

\subsubsection{Speed observer based on stator flux observer}

The stator flux observer involving a pure integrator has a problem in the perspective of practicality. A possible $\mathrm{dc}$ offset in the measured signal $\left(V-R_{s} I_{s}\right)$ may saturate the integrator. To avoid such a problem, a band pass filter, having a zero dc gain often replaces the integrals. However, it results in a sacrifice of the performance over the low speed rang. Normally, an observer employing a band pass filter does not perform well below $1 \mathrm{~Hz}$ range. This inability of the state flux observer in the low frequency introduces a fundamental limitation of speed sensorless. A modified stator flux observer is suggested [10], to overcome this problem. In this method the stator flux is estimated as follows;

$$
\begin{aligned}
& \lambda_{s d a s}=\int\left[v_{s d}-R_{s} i_{s d}-k_{0}\left(i_{s d c t}-i_{s d}\right)\right] d t \\
& \lambda_{s q u s}=\int\left[v_{s q}-R_{s} i_{s q}-k_{0 l}\left(i_{s q u s}-i_{s q}\right)\right] d t
\end{aligned}
$$

and is also estimated as follows;

$$
\begin{aligned}
& \hat{i}_{s d k s}=\int\left[k_{1} i_{s i t}-\left(k_{2} \lambda_{s q}\right)+\left(k_{3} \lambda_{s d e s}-i_{s q} \gamma_{e s s}+k_{3} V_{s d}-k_{4}\left({ }_{s d e s}-i_{s d}\right)\right] d t\right. \\
& i_{\text {sqes }}=\int\left[k_{1} i_{s q}+\left(k_{2} \lambda_{\text {ges }}\right)-\left(k_{3} \lambda_{\text {sges }}-i_{s q}\right) \omega_{e s}+k_{3} v_{s d}-k_{4}\left(i_{s d e s}{ }^{-i} i_{s d}\right)\right\} d x
\end{aligned}
$$

Then the speed is observed as:

$\omega_{e s}=K_{s} \int\left(t\left(\frac{\lambda_{\text {sqer }}}{\sigma L_{s}}-i_{s q}\right)\left(i_{s d e s}-i_{s d}\right)+\left(\frac{\lambda_{s d e s}}{\sigma L_{s}}-i_{s d}\right)\left(i_{s q e s}-i_{s q}\right)\right] d t$

where $k_{4}$ : current constant; $k_{0}$ flux constant and the subscript "es" denotes that estimated value.

A simulation for the system shown in Fig 5 with the help of Eqns (12) to (16) is carried-out using 
Matlab/Simulink. The motor performance is studied when the controller is driven using estimated speed based on the modified stator flux observer. The motor response due to a step change in the command speed is used to evaluate the performance in terms of steady state errors and stability. The motor is subjected to step increase and decrease in the reference speed under loading conditions to evaluate its performance. Figure 12 shows the estimated as well as the speed measured from simulation model. The command speed is set initially $150 \mathrm{rad} / \mathrm{s}$ at full load. After $0.6 \mathrm{~second}$, the speed reference is reduced to $120 \mathrm{rad} / \mathrm{s}$ and then returned to $150 \mathrm{rad} / \mathrm{s}$ after 0.5 second. It is noticed that the rotor speed is accelerated and decelerated smoothly to follow its reference. Figure 13 shows the motor developed torque which correspondingly increase and decrease during the step changes in the reference speed due to the dynamic states. The phase current is illustrated in Fig. 14 and shows good dynamic response.

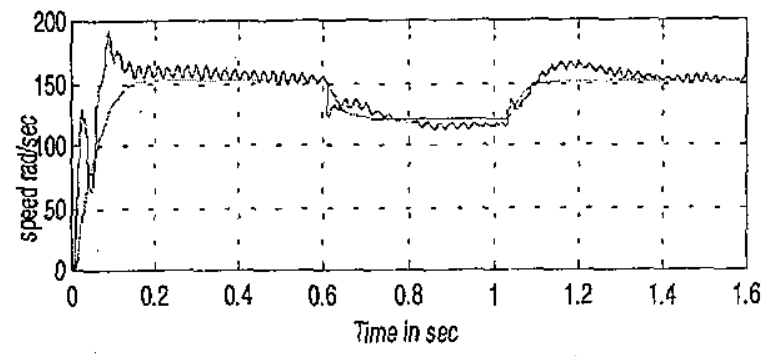

Fig. 12 The estimated and measured speeds.

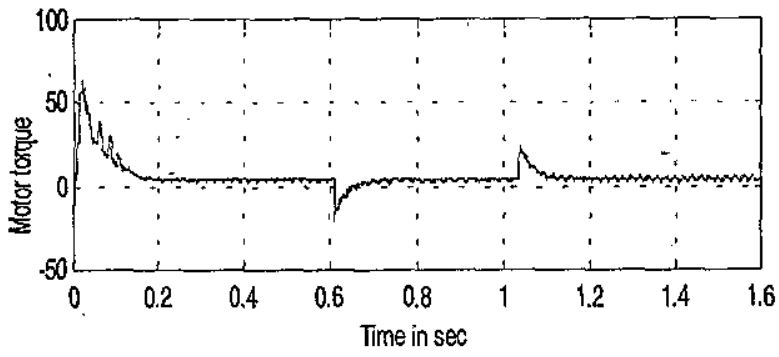

Fig. 13 The motor developed torque.

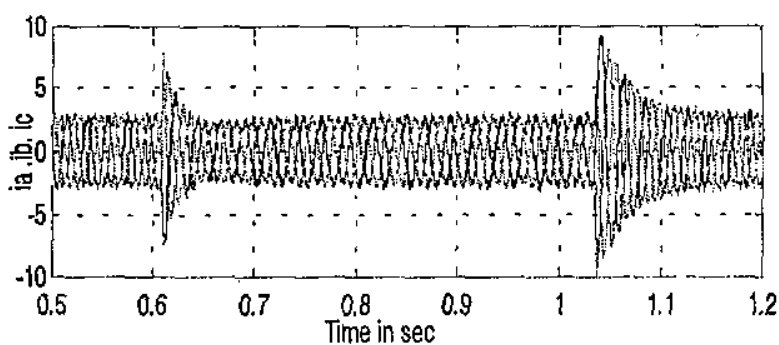

Fig. 14 The motor phase current

\subsubsection{Speed estimation based on rotor flux observer}

The induction motor can be described by the following state equation;

$\frac{d}{d t} x^{e}=A_{1} x^{c}+B_{1} v_{x}^{e}$

and the state observer becomes

$\frac{d}{d t} \bar{x}^{e}=\hat{A}_{1} \hat{x}^{e}+B_{1} v_{s}^{e}+G\left[\hat{i}_{s}^{e}-i_{s}^{e}\right]$

where $A$ is the motor parameter matrix and $G$ the observer gain matrix .

The adaptive observer is unstable in a small area in regenerating mode at low speeds. Many researchers attempted to find out the observer gain which stabilizes the system under any condition. To investigate the stability, the adaptive observer is linearzed around the operating point. And the motor speed is estimated by the following adaptive law:

$$
\begin{aligned}
\hat{\omega}_{e s}= & K_{s}\left(e_{i d s}^{e} \hat{\phi}_{q r}^{e}-e_{i q s}^{e} \hat{\phi}_{d r}^{e}\right) \\
& +K_{i} \int\left[\left(e_{i d s}^{e} \delta_{q r}^{e}-e_{i q s}^{e} \tilde{\phi}_{d r}^{e}\right)\right] d t
\end{aligned}
$$

A simulation of the system shown in Fig 5 with the help of Eqns (17) to (19) is carried-out using Matlab/Simulink. The motor performance is studied when the controller is driven using estimated speed based on the modified rotor flux observer. Figure 15 shows the estimated speed as well as the speed measured from simulation model. Figure 16 shows the motor developed torque. The motor phase current and its reference is illustrated in Fig. 17 which shows that good orientation with speed sensorless. Fig. 18 shows balanced three-phase current with good performance and waveform.

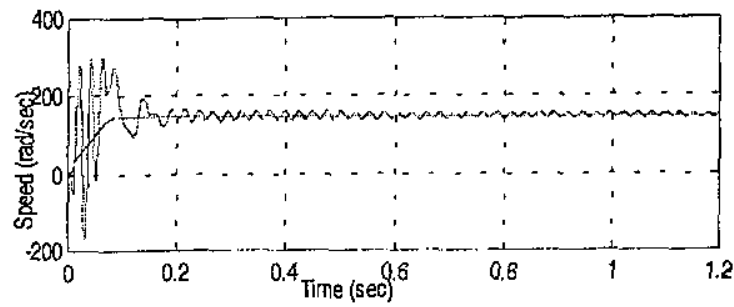

Fig. 15 The estimated speed and speed measured from simulation model.

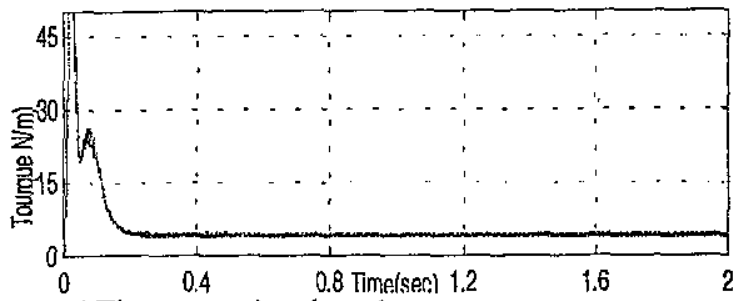

Fig. 16 The motor developed torque. 


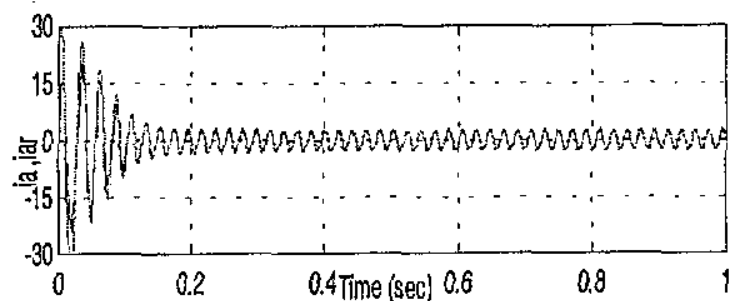

Fig 17 The motor phase current

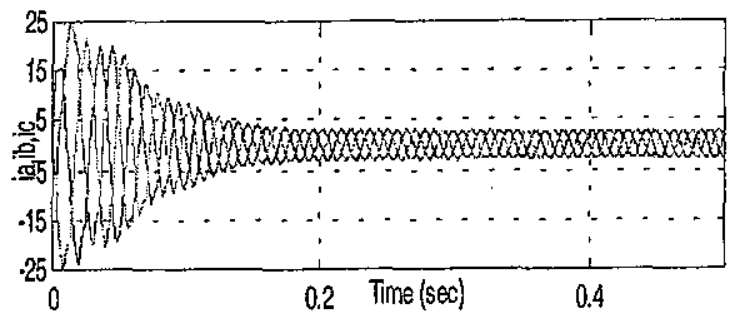

Fig 18 Three motor phase current

\section{THE PROPOSED SPEED OBSERVER}

A new rotor speed estimation method is proposed to improve the performance of a sensorless vector controlled induction motor in low speed range and regenerative mode as shown in Fig. 19. The proposed observer depends on both MRAS and the previous speed observer which is based on rotor flux. Speed estimation procedure of the proposed method is illustrated by the following analysis,

From the induction motor model depending on the stator current and rotor flux as output states.

The stator current is represented as:

$i_{d s}=\frac{1}{L m}\left[\lambda_{d r}+\omega_{r} T_{r} \lambda_{g r}+T_{r} p \lambda_{d r}\right]$

$i_{q s}=\frac{1}{L m}\left[\lambda_{q r}=\omega_{r} T_{r} \lambda_{q r}+T_{r} p \lambda_{q r}\right]$

Using the above equations, and estimated instead of measured speed, the stator current is estimated as

$\hat{i}_{d s}=\frac{1}{L m}\left[\lambda_{d r}+\hat{\omega}_{r} T_{r} \lambda_{q r}+T_{r} p \lambda_{d r}\right]$

$\hat{i}_{q s}=\frac{1}{L m}\left[\lambda_{q r}-\hat{\omega}_{r} T_{r} \lambda_{q r}+T_{r} p \lambda_{q r}\right]$

The difference in the stator current is obtained as

$i_{d s}-\hat{i}_{d s}=\frac{T_{r}}{L m} \lambda_{\varphi r}\left[\omega_{r}-\hat{\omega}_{r}\right]$

$\hat{i}_{q s}-i_{q s}=\frac{T_{r}}{L m} \lambda_{d r}\left[\omega_{r}-\hat{\omega}_{r}\right]$

Multipling by the rotor flux and adding them together;

$$
\begin{aligned}
& \left(i_{d s}-\hat{i}_{d s}\right) \lambda_{q r}=\frac{T_{r}}{L m} \lambda_{q r}^{2}\left[\omega_{r}-\bar{\omega}_{r}\right] \\
& \left(\hat{i}_{q s}-i_{q s}\right) \lambda_{d r}=\frac{T_{r}}{L m} \lambda_{d r}^{2}\left[\omega_{r}-\hat{\omega}_{r}\right]
\end{aligned}
$$

By summing the above two equations.

$$
\left(i_{d s}-\hat{i}_{d s}\right) \lambda_{q r}+\left(\hat{i}_{q s}-i_{q s}\right) \lambda_{d r}=\frac{T_{r}}{L m}\left(\lambda_{q r}^{2}+\stackrel{\lambda}{\lambda} d r^{2}\right)\left[\omega_{r}-\hat{\omega}_{r}\right](24)
$$

Hence, the error of the rotor speed is obtained as follows:

$$
\begin{aligned}
& \omega_{r}-\hat{\omega}_{r}=\left[\left(i_{d s}-\hat{i}_{d s}\right) \lambda_{q r}-\left(i_{q v}-\hat{i}_{q v}\right) \lambda_{d r}\right] / K \\
& \text { Where } \quad K=\frac{T_{r}}{L m}\left(\lambda_{q r}^{2}+\hat{\lambda}_{d r}\right)
\end{aligned}
$$

The right hand term seems as the term of speed calculation from adaptive observer, so the speed can be calculated from the following equation:

$$
\begin{array}{r}
\hat{\omega}_{r}=\frac{1}{K}\left[\left(K_{p}\left(i_{d s}-\hat{i}_{d s}\right) \lambda_{q r}-\left(i_{q s}-\vec{i}_{q s}\right) \lambda_{d r}\right)+\right. \\
\left.\left(K_{1} \int\left(i_{d s}-\hat{i}_{d s}\right) \lambda_{q r}-\left(i_{q s}-\hat{i}_{q s}\right) \lambda_{d r}\right)\right]
\end{array}
$$

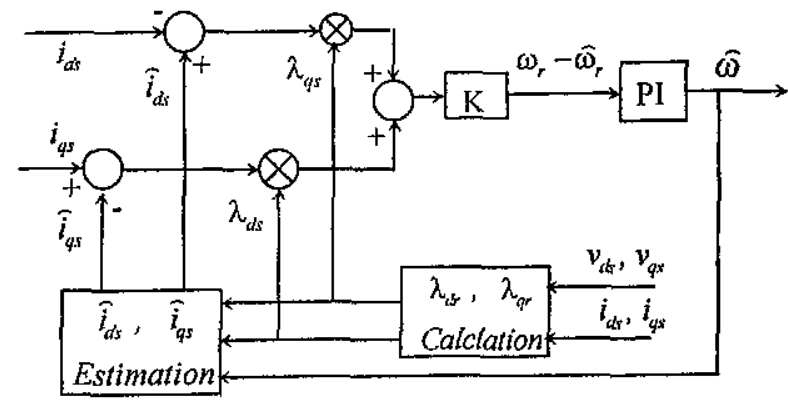

Fig. 19 Configuration of the proposed MARAS

A simulation of the system shown in Fig. 5 with the help of Eqns (20) to (26) is carried-out using Matlab/Simulink. The motor performance is studied when the controller is driven using the proposed speed observer. The response due to speed reverse in the command speed is used to evaluate the performance in terms of steady state errors and stability. Figure 20 shows the estimated speed as well as the speed measured from simulation model. It can be seen that the rotor speed is accelerated and decelerated smoothly to follow its reference value. Figure 21 shows the motor developed torque which correspondingly increase and decrease during the step changes in the reference speed due to the dynamic states. The three phase currents are illustrated in Fig. 22 and show good dynamic response. 


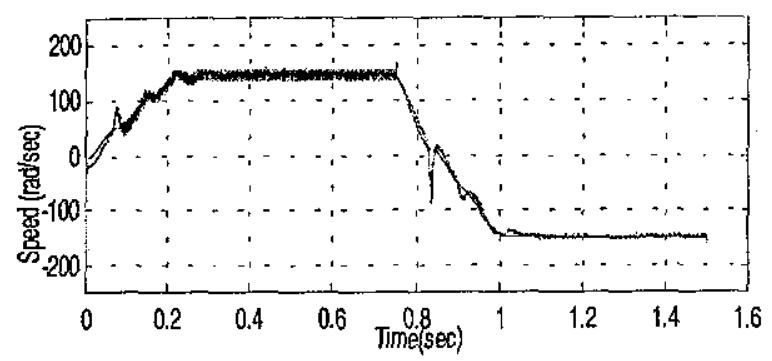

Fig. 20 The estimated and measured speeds

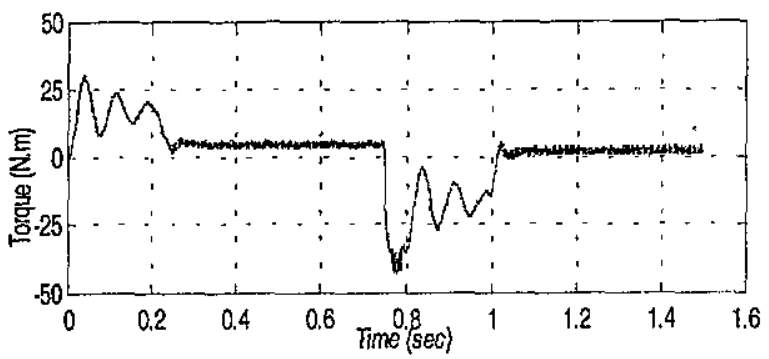

Fig. 21 The motor developed torque

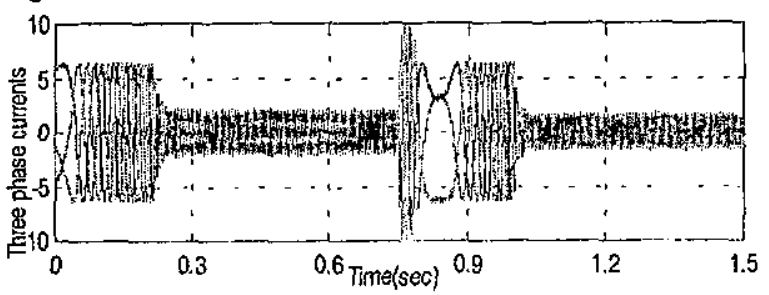

Fig. 22 Three phase motor current

\section{5- CONCLUSION}

A four quadrant rotor speed estimation method using MRAC was proposed to improve the performance of a sensorless vector controller. In the proposed method, the stator current is used as the state variable for estimating the speed. In conventional MRAC methods, the difference between state variables obtained by reference model and adjustable one has the unclear relationship with the speed estimation error. In the proposed method, the stator current error is represented as a function of the first degree for the error value in the speed estimation. Also, the proposed method is robust to variations in the stator resistance. In particular, the proposed method is extremely robust to variations in the mutual inductance. As a result, the proposed method can produce an excellent speed estimation performance for four-quadrant speed operation.
List Principal Symbols;

$$
\begin{aligned}
& L_{\sigma}=L_{s}-\frac{L_{m}^{2}}{L_{r}} \quad T_{r}=\frac{L_{r}}{R_{r}} \\
& k_{1}=-\frac{R_{s}}{\sigma L_{s}}-\frac{L_{m}^{2}}{\sigma L_{k} L_{r} T_{r}}-\frac{1}{T_{r}} \\
& k_{2}=\frac{1}{\sigma L_{s} T_{r}} \quad k_{3}=\frac{1}{\sigma L_{k}} \\
& b_{1}=\frac{1}{\sigma L s} \quad \sigma=1-\frac{\mathrm{L}_{\mathrm{m}}^{2}}{\mathrm{~L}_{s} L_{r}}
\end{aligned}
$$

$V_{\text {qse, }}, V_{d s e}$

$\mathrm{I}_{\mathrm{qse}}, \mathrm{I}_{\mathrm{dse}}$

$\lambda_{\mathrm{qse}}, \lambda$

$\mathrm{R}_{\mathrm{s}}, \mathrm{R}_{\mathrm{r}}$

$\mathrm{J}, \mathrm{B}$ $\mathrm{q}^{\mathrm{e}}-\mathrm{d}^{\mathrm{e}}$-axis stator voltage $\mathrm{q}^{\mathrm{e}}-\mathrm{d}^{\mathrm{e}}$-axis stator current $q^{e}-d^{e}-$ axis stator flux linkage coefficients

$\mathrm{L}_{\mathrm{s}}, \mathrm{L}_{\mathrm{r}}, \mathrm{L}_{\mathrm{m}} \quad$ stator, rotor and mutual inductances $\mathrm{T}_{\mathrm{e}}, \mathrm{T}_{\mathrm{L}} \quad$ electromagnetic and load torque

\section{REFERENCES.}

[1] Holtz, J., "Methods for Speed Sensorless Control of AC Drives", Proceedings of IEEE-IECON'93, PP 415-420.

[2] J.Holtz, "Sensorerless Control of Induction Motor Drives" proceedings of IEEE, Vol.90. No.8, 2002.pp.1359-1394.

[3] Schauder, C., "Adaptive Speed Identification for Vector Control of Induction Motors without Rotational Transducers", IEEE-IA, Vol. 28, No. 5, Sept./Oct. 1992, PP 1054-1061,.

[4] F.Z.Pengo T.Fukao "Robust Speed Identification For Sensorless Vector Control of Induction Motors", IEEJ-IAS 1993, Annual meeting, Japan, PP 219-220.

[5] M.Elloumi , L.Ben Brahim and M.A. Al Hamadi "Survey of Speed Sensorless Control for Induction IM Drives", IECON'98, Germany, Vol. 2, August/Sept. 1998, PP 1018-1023.

[6] Ilas, C., Bettini, A., Ferraris, L., Griva, G., Profumo, F., "Comparison of Different Schemes without Shaft Sensors for Field Oriented Control Drives", Proceedings of the IEEE-lECON'94 PP. 1579-1588.

[7] M.Jemli, M.Boussak, M. Godda and M.B.A.Kamoun, "MRAS Identification Schemes for Sensorless Indirect Field Oriented Control Of Induction Motor Drives With Rotor Resistance Tuning" Proc. of ICEM, Turkey 1998, PP 15721577 ,

[8] M.N. Marwali, A. Keyhani, "A comparative study of rotor flux based MRAS and back EMF based MRAS speed estimators for speed sensorless vector 
Z. Salem, M. Khater, S. Kalilah, S. Mahmoud "Four-Quadrant Speed Estimation Based On Model..."

control of induction machines", IEEE-IAS Annual Meeting, 1997, PP 160- 166.

[9] R. Blasco -Gimenez, G.M. Asher, M. Sumner, K.J. Bradley, "Dynamic performance limitations of MRAS based sensorless induction motor drives. Part 1. Stability analysis for the closed loop drive", IEE Proc, Pt B, Vol 143, 1996, PP 113-122.

[10] N.Hur, K.Hong and K.Nam "Robust Adaptive sensorless Field oriented Control Using Modified Stator Flux Observer", IEEE-IA, Vol. 97, No. 2, Mar/Apr. 1997, PP 1050-1054.

[11] H.Kubota ,I. Sato, Y.Tamura, K. Matsuse, Hisayoshi Ohta, and Y.Hori, "Regenerating Mode
Low-Speed operation of Sensorless Induction Motor Drive With Adaptive Observer". IEEE, Vol. 38, No. 4, July/August 2002, PP 1080-1086

[12] Kubota, H., Matsuse, K. and Nakano, T.,"DSP. Based Speed Adaptive Flux Observer of Induction Motor", IEEE-IA, Vol. 29, No. 2, Mar./Apr. 1993, PP 344-348.

[13] H. Tajima and Y. Hori, ,speed Sensor-Less FieldOrientationControl of the Induction Machine", IEEE-IA, Vol. 29, No. 1, Jan/Feb. 1993, pp. 175180. 